\title{
Differences in Aerobic Fitness and Lifestyle Characteristics in Preschoolers according to their Weight Status and Sports Club Participation
}

\author{
Vincent Ebenegger ${ }^{\mathrm{a}} \quad$ Pedro Marques-Vidal ${ }^{\mathrm{b}}$ Susi Kriemler ${ }^{\mathrm{c}} \mathrm{d}$ \\ Andreas Nydegger ${ }^{\mathrm{e}} \quad$ Lukas Zahner $^{c} \quad$ Iris Niederer $^{c} \quad$ Flavia Bürgic \\ Jardena J. Puder ${ }^{f}$ \\ ${ }^{a}$ Institute of Sports Sciences, University of Lausanne, ${ }^{b}$ Institute of Social and Preventive \\ Medicine, University Hospital Center and Faculty of Biology and Medicine, Lausanne, ' Swiss \\ Tropical and Public Health Institute, ${ }^{d}$ Institute of Exercise and Health Sciences, University \\ of Basel, Basel, e Pediatric Gastroenterology Unit, Department of Pediatrics, ${ }^{f}$ Service of \\ Endocrinology, Diabetes and Metabolism, University of Lausanne, Centre Hospitalier \\ Universitaire Vaudois, Lausanne, Switzerland
}

\section{Key Words}

Overweight $\cdot$ Physical fitness $\cdot$ Sedentary lifestyle $\cdot$ Children $\cdot$ Nutrition

\begin{abstract}
Objective: This study assesses differences in adiposity, aerobic fitness, and lifestyle characteristics in preschoolers according to their weight status and sports club (SC) participation. Method: As part of the Ballabeina study, 600 randomly selected preschoolers (mean age 5.1 \pm 0.6 years; $50.2 \%$ girls) were analyzed. Body composition was measured by bioelectrical impedance, aerobic fitness by the 20 -meter shuttle run test, and physical activity by accelerometers. Eating habits, media use, and SC participation were assessed by questionnaires. Results: Overweight children (Swiss national percentiles) and children not participating in SC had both lower aerobic fitness and higher \% body fat compared to their respective counterparts (all $p \leq 0.028$ ). In addition, children not participating in SC were less physically active, had more media use, and ate less healthy compared to children participating in SC (all $p \leq 0.023$ ). Controlling for parental sociocultural determinants attenuated differences in \% body fat, in physical activity, and in eating habits. Conclusion: Aerobic fitness differs both according to weight status and SC participation in preschoolers. Furthermore, in view of the many differences in lifestyle behaviors, SC participation at this age could represent a more discriminatory indicator of healthy lifestyle characteristics than weight status.
\end{abstract}




\section{Introduction}

Children's lifestyles have unfavorably changed during the last decades: reported physical activity (PA) [1] and aerobic fitness have decreased [2], while media use [3] and unhealthy eating habits have increased [4]. These changes are of concern because they have a deleterious effect on childhood overweight (OW) and health.

Cross-sectional studies in schoolchildren have shown that OW children have lower aerobic fitness compared to their normal-weight counterparts [5-7]. Although OW schoolchildren seem to be less physically active [8], it is controversial if weight status-related differences in PA already exist in preschoolers [9-11]. Differences in study times might to some extent explain the differences in PA. To our knowledge, weight status-related differences in aerobic fitness have not been investigated in preschoolers. Furthermore, most studies conducted in preschool children found differences in media use [12,13], but not in eating habits $[14,15]$ between OW and normal-weight children.

Sports club (SC) participation represents a modifiable determinant for potential beneficial changes in adiposity, fitness and lifestyle characteristics, and its implementation is feasible on a large scale. However, it is unclear if observed differences between children participating or not in SCs are in fact due to SC participation or due to a healthy family lifestyle or parental support for PA. Thus, SC participation could be a mediator or a marker of fitness and a healthy family lifestyle. Indeed, schoolchildren who participate in sports activities generally have higher aerobic fitness [16, 17], higher PA [16, 18], less media use [18], and healthier eating habits [19] compared to their counterparts. However, SC-related differences in body fatseem to depend on the amount of sports practiced $[16,17]$. To our knowledge, only two studies focused on SC participation in preschoolers. The first one reported less media use in children who participate in SC [12], while no differences in PA was demonstrated in the second [11]. Although SC participation starts at preschool age in many countries, there is no trial in young children investigating in a single study if there are differences in adiposity, aerobic fitness, and overall healthy lifestyle according to SC participation. Therefore, our objective was to assess differences in adiposity, PA, aerobic fitness, media use, and various eating habits in 4- to 6-year-old children according to their weight status and SC participation, while accounting for potential sociocultural confounders. We hypothesized that at this young age group, many differences would be seen according to their weight status, but only few according to their SC participation.

\section{Material and Methods}

\section{Design and Participants}

Baseline data from the Ballabeina study (http://clinicaltrials.gov NCT00674544) were collected in the late summer of 2008 and used for this current analysis. The study randomly selected 40 classes from areas with a high migrant prevalence (i.e. $\geq 40 \%$ ) in two Swiss cantons, and its methodology has been reported previously [20]. This study was approved by the local respective ethical committees, and the parents or legal representatives of each child provided written informed consent.

Of the initial 727 preschool children, 655 consented (participation rate $90.1 \%$ ). The current analysis included 600 children who had complete data for all variables studied. 


\section{Measurements}

\section{Adiposity}

Standing height was determined and body weight was measured using an electronic scale (Seca, Basel, Switzerland; accuracy $0.05 \mathrm{~kg}$ ) to calculate BMI. Children were classified into weight status groups according to Swiss national percentiles [21], as national percentiles are known to be more sensitive than the international ones [22]. To help readers from other countries to extrapolate from our population to their own, we also classified children according to the International Obesity Task Force (IOTF) criteria [23]. For both grow curves, children with a BMI $\geq 97$ th percentile were considered obese, those with a BMI $\geq 90$ th percentile OW/obese and those with a BMI <90th percentile normal weight. \% body fat was estimated by a four-polar single frequency bioelectrical impedance device (RJL Systems, Model 101A; Detroit, MI, USA), based on a formula previously validated in a comparable population: Lean mass $=((0.77$ $\times$ gender $)+(0.46 \times$ age $)+(0.32 \times$ weight $)+\left(0.41 \times\right.$ height $^{2} /$ resistance $\left.)-0.77\right)$, with boys $=1$ and girls $=0$, age in years, weight in $\mathrm{kg}$ and height in $\mathrm{cm}[24]$.

\section{Physical Activity}

PA was measured with a Computer Science and Applications (CSA) activity monitor (GT1M, Actigraph, Pensacola, FL, USA), set to save data in 15-second intervals (epochs) [20,25] as this interval has been shown to be adequate to detect the spontaneous activities of preschool children [25]. The CSA Actigraph is the most studied motion sensor in children and there is extensive evidence for a good reproducibility, validity, and feasibility [26]. This particular type of PA assessment has been shown to be valid across different activities in preschool children, with a Pearson correlation coefficient of $r=0.82$ between $\mathrm{VO}_{2}(\mathrm{ml} / \mathrm{kg} / \mathrm{min})$ and Actigraph counts $/ 15 \mathrm{~s}$ [25]. The accelerometers were worn around the hip during 5 consecutive days. Validity was defined as at least 3 days of recording ( 2 weekdays and 1 day on the weekend) [27], with a minimum of $6 \mathrm{~h}$ registration/day to include as much children as possible. The 6-hour validity was highly correlated with 10 -hour validity $(n=502, r=0.92, p<0.001)$. Data from monitored days were extrapolated by weighing weekdays and weekends (5:2). Sequences of at least 10 min of consecutive zero values were removed and interpreted as accelerometer not worn [28]. Total PA was expressed as counts per minute divided by daily wearing time (mean daily wearing time: $10.8 \pm 1.2 \mathrm{~h}$ ). Moderatevigorous and vigorous PA were defined as the number of 15-second intervals per hour spent in activities of $\geq 420$ counts and $\geq 842$ counts, respectively [25].

\section{Aerobic Fitness}

The multistage 20-meter shuttle run test was used to assess aerobic fitness [29, 30]. This test measures aerobic capacity by letting the child run back and forth for $20 \mathrm{~m}$ with an initial speed of $8 \mathrm{~km} / \mathrm{h}$ and a progressive $0.5 \mathrm{~km} / \mathrm{h}$ increase of the running speed every minute indicated by a sound. The highest stage reached describes the peak aerobic performance, i.e. the highest performed speed corresponding to the time sustained in the test [30]. The maximal performance was determined when the child could no longer follow the pace or the child decided itself to stop because of exhaustion. The test results were expressed as stages ( 1 stage is approximately $1 \mathrm{~min}$ ). The 20 -meter shuttle run test has been found to be a reliable (test-retest $r=0.73-0.93$ ] [29] and valid measure of maximum oxygen consumption as measured by treadmill testing $(r=0.69-0.87)$ [31]. Some formal adaptations of the original test were made due to the very young age of the children by having an adult running with the children until the end of the test to provide adequate pace. Intraobserver correlation for children aged 4-6 years was measured in our pilot study $(\mathrm{n}=20)$ and was $\mathrm{r}=0.84(\mathrm{p}<0.001)$.

\section{Eating Habits}

Eating habits were assessed using a semi-qualitative food frequency questionnaire validated in an identical population within the same study regions [32]. For the analysis of the questionnaire, all response options were recorded as daily frequencies, and the answers to the respective items were summed up to correspond to the 5 messages and their components developed by The Swiss Nutrition Society (www.sge-ssn.ch/fileadmin/ pdf/100-ernaehrungsthemen/70-altersspezifische_ernaehrung/2-kinder/ernaehrungsscheibe/Nutrition_disk. $p d f$ ). The five messages were based on factors implicated in childhood obesity: i) 'Drink water' (drinking water and decreasing sweetened drinks), ii) 'Eat fruit and vegetables' (eating fruits and vegetables), iii) 'Eat regularly' (eating meals regularly), iv) 'Make clever choices' (reducing fatty and sweet foods) and v) 'Turn your screen off when you eat' (reducing the intake of meals and snacks in front of television (TV)). 


\section{General Information}

Parental body weight, height, place of birth, and educational level were assessed by questionnaire [20]. Parental migrant status was determined according to the place of birth. Migrants were defined as at least one parent born outside Switzerland $[17,32]$ and low educational level as at least one parent with no education beyond obligatory school ( 9 years). Further questions included media use (defined by time spent by children with TV viewing and video game playing (min/day)) as well as children's and parents' participation in a SC. Both children and parents were asked if they are engaged in a SC and given a yes or no option. In children, the type of sports and the number of sessions per week were also asked [20]. Parental OW/obesity and SC participation were defined as at least one OW/obese parent (BMI $\geq 25 \mathrm{~kg}$ / $\mathrm{m}^{2}$ ) or as at least one parent participating in SCs.

Whenever needed, teachers or specific translators provided assistance for filling up the questionnaires.

\section{Statistical Analyses}

Statistical analyses were conducted using SPSS version 16.0 (SPSS Inc, Chicago, IL, USA). Data are summarized as mean (standard deviation) for normally distributed variables, as median (interquartile range) for skewed variables, and as percentages for categorical variables. For the analysis, children's weight status and SC participation were categorized in two groups (OW/obese vs. nor mal weight or obese vs. normal weight and non-SC participation vs. SC participation). Sex differences in age, parental migrant status and educational level, weight status, and SC participation were assessed with the chi square test. Linear and logistic regression analyses were performed for continuous and categorical variables, respectively, with adiposity, aerobic fitness, and lifestyle characteristics as well as certain parental characteristics as the outcome and children's weight status or SC participation as the predictor variables. As few differences in sex and age as well as parental migrant status and educational level were found between weight status of SC participating groups, analyses concerning children's characteristics were subsequently adjusted for these potential confounders. We also tested if differences in children's characteristics according to weight status or SC participation were mediated by parental weight status or parental SC participation by adjusting the analyses for these parameters. Interactions between SC participation and age or sex as well as between weight status and age or sex were also tested. For children and parents, both sexes were pooled for simplicity and lack of interaction with sex. Statistical significance was set at $\mathrm{p}<0.050$.

\section{Results}

\section{Baseline Characteristics}

Of the 600 children (5.1 \pm 0.6 years; $50.2 \%$ girls, table 1), 182 participated in SCs. According to the Swiss national percentiles, 120 children were OW/obese, and 65 obese. A more detailed description of the sample is shown in table 1.

\section{Differences in Adiposity, Aerobic Fitness, and Lifestyle Characteristics according to \\ Children's Weight Status}

OW/obese children had higher \% body fat, lower aerobic fitness, and more daily servings of water compared to normal-weight children (both $\mathrm{p} \leq 0.040$, table 2). There were no significant differences in PA, media use, and all the other eating habits (all $p \geq 0.054$ ). Comparing normal-weight with obese children revealed the same results as comparing normal-weight with OW/obese children (data not shown). Adjusting for sex and age as well as parental migrant status and educational level did not alter these results (table 2). Similarly, adjusting for parental weight status or parental SC participation did not alter these results, except that the borderline significant differences in vigorous PA became significant in favor of the normal-weight children (both $\mathrm{p}=0.034$, data not shown). In addition, after 
Table 1. Baseline characteristics of the studied population

\begin{tabular}{|c|c|c|c|c|}
\hline & $\begin{array}{l}\text { Whole population } \\
(\mathrm{n}=600)\end{array}$ & $\begin{array}{l}\text { Girls } \\
(\mathrm{n}=301 ; 50.2 \%)\end{array}$ & $\begin{array}{l}\text { Boys } \\
(\mathrm{n}=299 ; 49.8 \%)\end{array}$ & $\begin{array}{l}\mathrm{p} \text { values } \\
\text { (chi square) }\end{array}$ \\
\hline Age $e^{a}$ years & $5.1(0.6)$ & $5.2(0.6)$ & $5.1(0.6)$ & 0.213 \\
\hline Parental migrant status, $n$ (\%) & & & & 0.598 \\
\hline Non-migrants & $162(27.0)$ & $84(72)$ & $78(26.1)$ & \\
\hline Migrants ${ }^{b}$ of $c$ & $437(73.0)$ & $216(28)$ & $221(73.9)$ & \\
\hline Former Yugoslavia & $102(23.3)$ & $52(24.1)$ & $50(22.6)$ & \\
\hline Portugal & $85(19.4)$ & $41(19.0)$ & 44 (19.9) & \\
\hline Rest of Europe & $127(29.1)$ & $66(30.5)$ & $61(27.6)$ & \\
\hline Africa & $48(11.0)$ & 25 (11.6) & $23(10.4)$ & \\
\hline Rest of the World & $75(17.2)$ & $32(14.8)$ & $43(19.5)$ & \\
\hline Parental educational level, $n$ (\%) & & & & 0.263 \\
\hline Medium/high & $349(62.2)$ & $169(59.9)$ & $180(64.5)$ & \\
\hline Low $^{d}$ & $212(37.8)$ & $113(40.1)$ & $99(35.5)$ & \\
\hline \multicolumn{5}{|l|}{ Weight status, $n(\%)$} \\
\hline Swiss national percentiles & & & & 0.327 \\
\hline Normal weight & $480(80.0)$ & $236(78.4)$ & $244(81.6)$ & \\
\hline Overweight/obese ${ }^{e}$, of which & $120(20.0)$ & $65(21.6)$ & $55(18.4)$ & \\
\hline Obesef & $65(10.8)$ & $28(9.3)$ & $37(12.4)$ & \\
\hline International Obesity Task Force percentiles & & & & 0.547 \\
\hline Normal weight & $529(88.2)$ & $263(87.4)$ & $265(89.0))$ & \\
\hline Overweight/obesee, of which & $71(11.8)$ & $31(12.6)$ & $25(11)$ & \\
\hline Obese $^{f}$ & $15(2.5)$ & $7(2.3)$ & $8(2.7)$ & \\
\hline Sports club participation, $n(\%)$ & & & & 0.404 \\
\hline Non-participation & $418(69.7)$ & $205(68.1)$ & $213(71.2)$ & \\
\hline Participation atg & $182(30.3)$ & $96(31.9)$ & $86(28.8)$ & \\
\hline Gym & $69(37.9)$ & $42(43.8)$ & $27(31.4)$ & \\
\hline Team sports (mostly soccer) & 34 (18.7) & $0(0.0)$ & $34(39.5)$ & \\
\hline Swimming & $33(18.1)$ & $20(20.8)$ & $13(15.1)$ & \\
\hline Dance & $28(15.4)$ & $27(28.1)$ & $1(1.2)$ & \\
\hline Martial Arts & $8(4.4)$ & $3(3.1)$ & $5(5.8)$ & \\
\hline Others & $9(4.9)$ & $4(4.2)$ & $5(5.8)$ & \\
\hline No answers & $1(0.6)$ & $0(0.0)$ & $1(1.2)$ & \\
\hline \multicolumn{5}{|l|}{ Number of sessions per week } \\
\hline 1 & $163(89.6)$ & $92(95.8)$ & $71(82.6)$ & \\
\hline$\geq 2$ & $15(8.2)$ & $3(3.1)$ & 12 (13.9) & \\
\hline No answers & $4(2.2)$ & $1(1.1)$ & $3(3.5)$ & \\
\hline
\end{tabular}

aExpressed as mean (standard deviation).

bAt least one parent born outside Switzerland.

cPercentages are based on the 437 children with migrant parents.

${ }^{d} A t$ least one parent with no education beyond obligatory school ( 9 years).

eBMI $\geq 90$ th percentile.

$\mathrm{fBMI} \geq 97$ th percentile.

gPercentages are based on the 182 children participating in sports club. 
Table 2. Differences in adiposity, aerobic fitness and lifestyle characteristics according to children's weight status ${ }^{\mathrm{a}}$

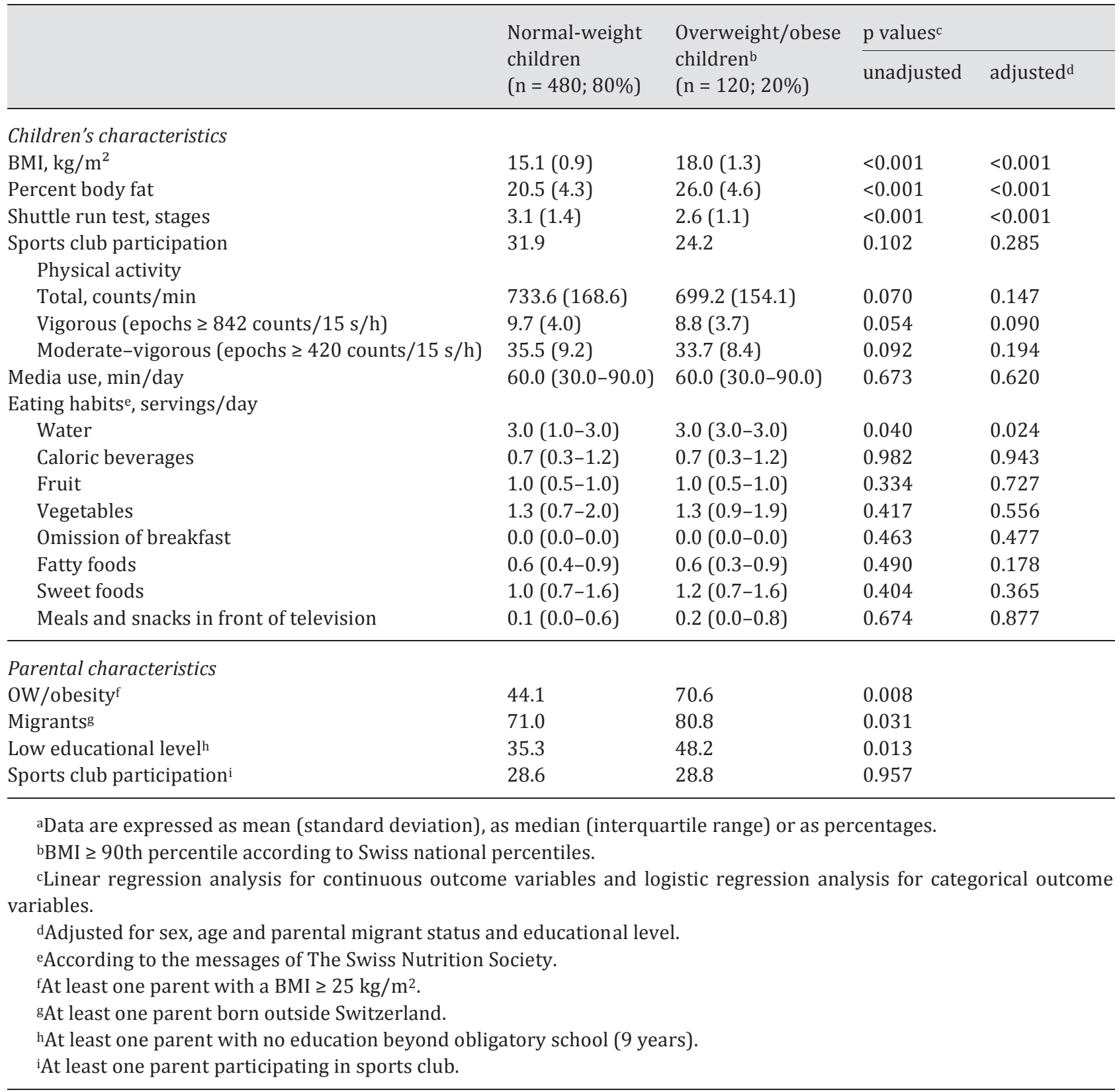

adjustment for parental weight status, differences in water consumption were no longer significant $(\mathrm{p}=0.098$, data not shown).

There were no interactions between weight status and age or sex.

Differences in Adiposity, Aerobic Fitness, and Lifestyle Characteristics according to Children's SC Participation

As presented in table 3, children not participating in SCs had increased \% body fat, decreased total PA, spent less time in vigorous PA, and had lower aerobic fitness and more 
Table 3. Differences in adiposity, aerobic fitness and lifestyle characteristics according to children's participation in sports club ${ }^{\mathrm{a}}$

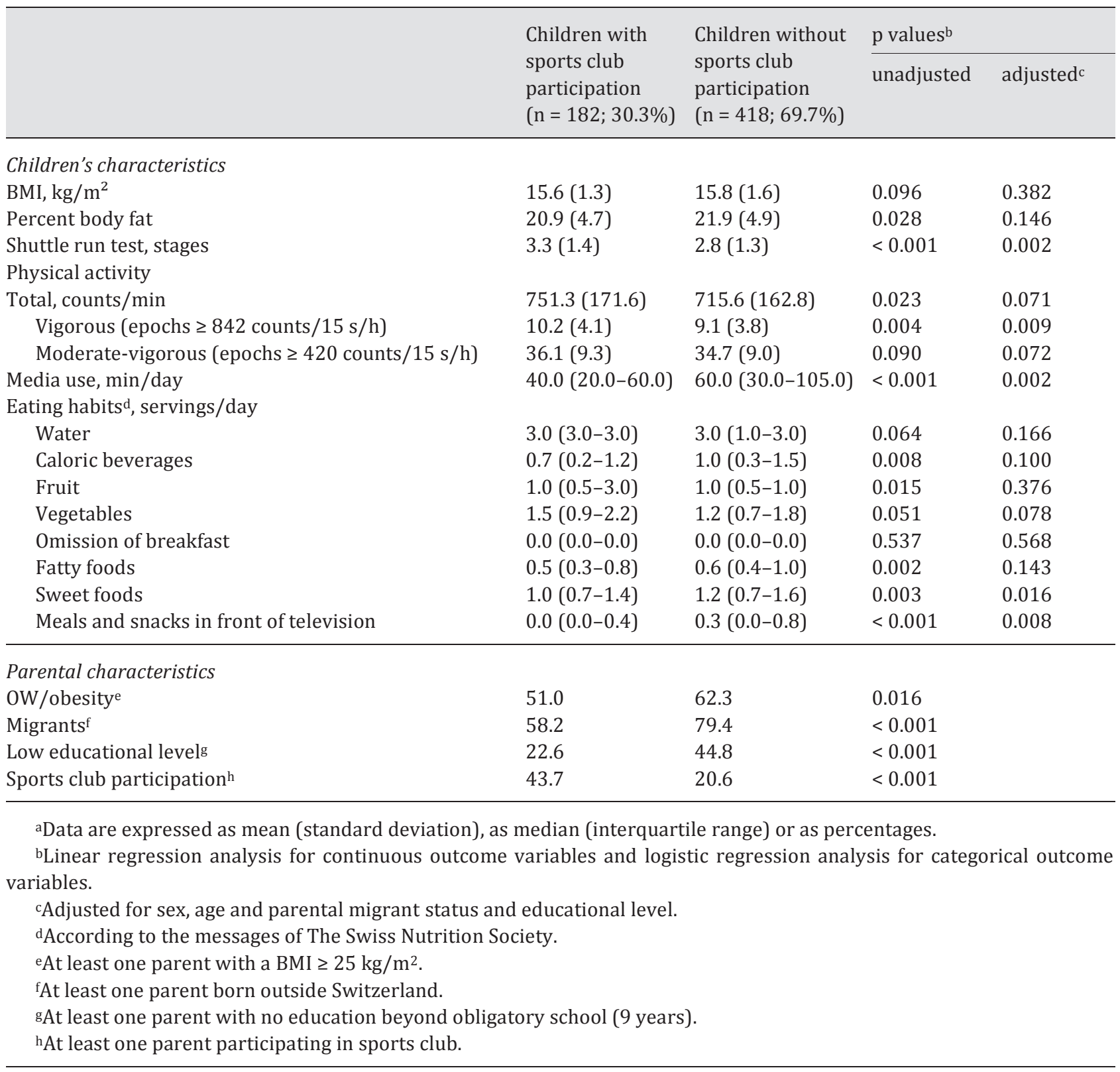

media use compared to children participating in SCs (all p $\leq$ 0.028). In addition, they had less healthy eating habits (fewer servings of fruit, more servings of caloric beverages, fatty foods, and sweet foods as well as more frequent eating in front of TV; all $p \leq 0.015$ ). After adjustment for sex and age as well as parental migrant status and educational level, differences in \% body fat, total PA, and some eating habits (fruit, caloric beverages and fatty foods) were no longer significant (all $p \geq 0.071$ ). After adjustment for parental weight status or SC participation, the borderline nonsignificant differences in water and vegetables consumption became significant in favor of the children participating in SCs (all p $\leq 0.044$, 
data not shown). In addition, after adjustment for parental weight status, differences in total PA and fruit consumption were no longer significant ( $p \geq 0.073$, data not shown) and after adjustment for parental SC participation differences in caloric beverages consumption were no longer significant $(\mathrm{p}=0.054)$.

There were no interactions between SC participation and age or sex.

\section{Discussion}

The purpose of this study was to identify differences in adiposity, PA, aerobic fitness, media use, and various eating habits in preschool children according to their weight status and SC participation. Although there were no gender differences in SC participation, girls were more engaged in gym and swimming and boys more in team sports. OW/obese children and children not participating in SCs had both lower aerobic fitness and higher \% body fat compared to their respective counterparts. In addition, children not participating in SCs were less physically active, had more media use, and ate less healthy compared to children participating in SCs. Hence, SC participation could represent a more discriminatory indicator of healthy lifestyle characteristics than weight status in preschoolers demonstrating particularly the importance of parental attitude and family lifestyle. Controlling for parental sociocultural determinants attenuated differences in $\%$ body fat, total PA, and eating habits [33], and controlling for parental weight status or SC participation attenuated some differences in total PA and in eating habits.

OW/obese preschool children had lower aerobic fitness compared to their normalweight peers, a finding which is in agreement with previous results obtained in schoolchildren [5-7]. This lower aerobic fitness at this early age is of concern, as it has been shown that lower aerobic fitness further aggravates the increased cardiovascular risk due to obesity [34,35]. The poorer performance in the 20 -meter shuttle run test of OW/obese children may be attributed to their excess body fat, which represents an extra load [36] though differences in weight were rather small. It may also be that these children already avoid certain activities because of the greater energy cost [37]. Surprisingly, there were no differences in PA and SC participation between OW/obese and normal-weight children. The former result is in accordance with some $[9,11]$ but not all $[10]$ data in young children. However, a prior report in preschoolers has found that $\mathrm{OW}$ girls participated more frequently in organized sports [12]. The authors explained their astonishing finding by a parental concern to prevent their children from becoming obese. In contrast to previous studies [12, 13], we did not find any weight status-related differences in sedentary behavior, regardless if media use or resting activity, measured by accelerometry (data not shown), were used as markers for sedentary behavior. Furthermore, similarly to the few existing data in preschoolers, we also reported no differences in eating habits [14, 15]. Therefore, it is possible that the presence of weight status-related differences in PA, sedentary behavior, and eating habits in young children might depend on the population studied and might even be too small to be detected.

Our findings confirm cross-sectional and longitudinal data demonstrating higher aerobic fitness $[16,17,38]$ and lower body fat $[16,38]$ in schoolchildren participating in SC. However, a previous study found no differences in body fat [17] and hypothesized that it might be due to less actual time spent in organized sports (in most instances only once a week) [17]. Indeed, in the other reports that showed differences in body fat [16, 38], sports participation was considered only if the children practiced at least $3 \mathrm{~h}$ of extracurricular activities per week. Interestingly, an intervention based on an after-school program of $3 \times$ 90 min of PA per week reduced \% body fat in the same age population [39]. In agreement 
with findings in older children [18, 19], children participating in SC had higher PA and spent more time in vigorous PA than children not participating in SC. This increase in PA may have contributed to their improved aerobic fitness and body composition [33, 34]. The fact that Finn et al. [11] did not document any differences in PA of preschoolers according to their participation in organized activities might be explained by their shorter measurement period of PA.

In the current study, most children participated once a week in SC activities. In addition, there was no interaction with age, and thus differences according to SC participation were similar in 4-year-old children that may not have been engaged for very long. Therefore, our results rather than being a direct consequence of the child's participation may rather represent a positive parental attitude and support towards PA and a general more active and healthy family life. The same could be true for some studies in schoolchildren, especially when SC participation is not more than once a week. This is crucial as the influence of parental attitude represents a potentially modifiable factor. In our analysis, controlling for parental SC participation altered few results. However, parental SC participation is also only one of many facets of parental attitude towards a healthy family lifestyle.

Previous data have documented less media use $[12,18]$ and healthier eating habits [19] in preschool and/or schoolchildren participating in sports activities. We also found the same differences in our population sample. In addition, it has been shown that children of active parents have higher levels of PA $[40,41]$ and participate more frequently in extracurricular sports $[17,42]$. Although we did not objectively assess parental PA, we observed significant differences in parental participation in SCs between children who participate in SCs and their no-participating counterparts.

Strengths of this study include a comprehensive assessment of adiposity, aerobic fitness, and lifestyle characteristics in a relatively large and randomly selected population of preschool children. It fills a gap in the more thorough investigation of various differences according to SC participation in young children. Another strength is the adjustment for sociocultural confounders which have not been controlled for in many previous reports. This study has also some limitations. First, its cross-sectional design limits the assessment of cause-effect relationships, and it is thus not clear if SC participation represent more a marker or a mediator of aerobic fitness and healthy lifestyles. Second, aerobic fitness was only tested by a field measure that represents an indirect measurement of $\mathrm{VO}_{2}$ max. This may dilute the relationship between SC participation and weight status with aerobic fitness. However, laboratory tests would not have been feasible in this epidemiological study, and at this age the 20-meter shuttle run test may reflect performance in real-life at least as good as more experimental settings. In addition, it is well possible that the children were much more motivated by performing this strenuous exercise together than if it would have been done individually. Third, the type of SC participation may play a role in influencing our outcomes, and there were varying types of SC activities with no control or assessment of the intensity. Thus, we actually did not know in detail what the children did during their SC participation.

In conclusion, aerobic fitness differs both according to weight status and SC participation in preschoolers. Furthermore, in view of the many observed differences in lifestyle behaviors, SC participation at this age could represent a more discriminatory indicator of healthy lifestyle characteristics than weight status. Considering their young age and the weak frequency of participation in SCs, the latter finding probably reflects a general more active and healthy family life and/or a positive parental attitude and support towards PA. 


\section{Acknowledgments}

We thank Professors R. Gaillard, S. Fanconi and F. Ohl who had helped to make this study possible. A special thank to all the children, their parents, the school teachers, and the respective school health services.

The 'Ballabeina' study was mainly supported by the Swiss National Science Foundation (Grant \# 3200B0-116837) and Health Promotion Switzerland (Project \# 2104). Additional funding was obtained from a research award for Interdisciplinary Research from the University of Lausanne, a Takeda research award, the Wyeth Foundation for the Health of Children and Adolescents, the Freie Akademische Gesellschaft, and an unrestricted educational grant from Nestlé.

\section{Disclosure Statement}

None of the authors has any competing financial interests or any conflict of interest.

\section{References}

1 Andersen LB, van Mechelen W: Are children of today less active than before and is their health in danger? What can we do? Scand J Med Sci Sports 2005;15:268-270.

- 2 Tomkinson GR, Leger LA, Olds TS, Cazorla G: Secular trends in the performance of children and adolescents (1980-2000): an analysis of 55 studies of the $20 \mathrm{~m}$ shuttle run test in 11 countries. Sports Med 2003;33: 285-300.

3 Caroli M, Argentieri L, Cardone M, Masi A: Role of television in childhood obesity prevention. Int J Obes Relat Metab Disord 2004;28(suppl 3):S104-108.

- 4 Nicklas TA, Demory-Luce D, Yang SJ, Baranowski T, Zakeri I, Berenson G: Children's food consumption patterns have changed over two decades (1973-1994): the Bogalusa heart study.J Am Diet Assoc 2004;104: $1127-1140$.

- 5 Tokmakidis SP, Kasambalis A, Christodoulos AD: Fitness levels of Greek primary schoolchildren in relationship to overweight and obesity. Eur J Pediatr 2006;165:867-874.

- 6 Hussey J, Bell C, Bennett K, O’Dwyer J, Gormley J: Relationship between the intensity of physical activity, inactivity, cardiorespiratory fitness and body composition in 7-10-year-old Dublin children. Br J Sports Med 2007;41:311-316.

- 7 Eisenmann JC, DuBose KD, Donnelly JE: Fatness, fitness, and insulin sensitivity among 7- to 9-year-old children. Obesity (Silver Spring) 2007;15:2135-2144.

- 8 Page A, Cooper AR, Stamatakis E, Foster LJ, Crowne EC, Sabin M, Shield JP: Physical activity patterns in nonobese and obese children assessed using minute-by-minute accelerometry. Int J Obes (Lond) 2005;29: 1070-1076.

- 9 Metallinos-Katsaras ES, Freedson PS, Fulton JE, Sherry B: The association between an objective measure of physical activity and weight status in preschoolers. Obesity (Silver Spring) 2007;15:686-694.

-10 Trost SG, Sirard JR, Dowda M, Pfeiffer KA, Pate RR: Physical activity in overweight and nonoverweight preschool children. Int J Obes Relat Metab Disord 2003;27:834-839.

-11 Finn K, Johannsen N, Specker B: Factors associated with physical activity in preschool children. J Pediatr 2002;140:81-85.

12 Jouret B, Ahluwalia N, Cristini C, Dupuy M, Negre-Pages L, Grandjean H, Tauber M: Factors associated with overweight in preschool-age children in southwestern France. Am J Clin Nutr 2007;85:1643-1649.

13 Jones RA, Okely AD, Gregory P, Cliff DP: Relationships between weight status and child, parent and community characteristics in preschool children. Int J Pediatr Obes 2009;4:54-60.

14 Davies PS: Diet composition and body mass index in pre-school children. Eur J Clin Nutr 1997;51:443-448.

-15 Jago R, Baranowski T, Baranowski JC, Thompson D, Greaves KA: BMI from 3-6 y of age is predicted by TV viewing and physical activity, not diet. Int J Obes (Lond) 2005;29:557-564.

-16 Ara I, Vicente-Rodriguez G, Jimenez-Ramirez J, Dorado C, Serrano-Sanchez JA, Calbet JA: Regular participation in sports is associated with enhanced physical fitness and lower fat mass in prepubertal boys. Int J Obes Relat Metab Disord 2004;28:1585-1593.

-17 Zahner L, Muehlbauer T, Schmid M, Meyer U, Puder JJ, Kriemler S: Association of sports club participation with fitness and fatness in children. Med Sci Sports Exerc 2009;41:344-350.

18 Sirard JR, Pfeiffer KA, Dowda M, Pate RR: Race differences in activity, fitness, and BMI in female eighth graders categorized by sports participation status. Pediatr Exerc Sci 2008;20:198-210.

19 Pate RR, Trost SG, Levin S, Dowda M: Sports participation and health-related behaviors among US youth. Arch Pediatr Adolesc Med 2000;154:904-911. 
20 Niederer I, Kriemler S, Zahner L, Burgi F, Ebenegger V, Hartmann T, Meyer U, Schindler C, Nydegger A, Marques-Vidal P, Puder JJ: Influence of a lifestyle intervention in preschool children on physiological and psychological parameters (Ballabeina): study design of a cluster randomized controlled trial. BMC Public Health 2009;9:94.

21 Prader A, Largo RH, Molinari L, Issler C: Physical growth of Swiss children from birth to 20 years of age. First Zurich longitudinal study of growth and development. Helv Paediatr Acta Suppl 1989;52:1-125.

-22 Reilly JJ: Assessment of obesity in children and adolescents: synthesis of recent systematic reviews and clinical guidelines. J Hum Nutr Diet 2010;23:205-211.

-23 Cole TJ, Bellizzi MC, Flegal KM, Dietz WH: Establishing a standard definition for child overweight and obesity worldwide: international survey. BMJ 2000;320:1240-1243.

24 Kriemler S, Puder J, Zahner L, Roth R, Braun-Fahrlander C, Bedogni G: Cross-validation of bioelectrical impedance analysis for the assessment of body composition in a representative sample of 6-to 13-year-old children. Eur J Clin Nutr 2008.

-25 Pate RR, Almeida MJ, McIver KL, Pfeiffer KA, Dowda M: Validation and calibration of an accelerometer in preschool children. Obesity (Silver Spring) 2006;14:2000-2006.

26 de Vries SI, Bakker I, Hopman-Rock M, Hirasing RA, van Mechelen W: Clinimetric review of motion sensors in children and adolescents. J Clin Epidemiol 2006;59:670-680.

27 Trost SG, Pate RR, Freedson PS, Sallis JF, Taylor WC: Using objective physical activity measures with youth: how many days of monitoring are needed? Med Sci Sports Exerc 2000;32:426-431.

-28 Baquet G, Stratton G, Van Praagh E, Berthoin S: Improving physical activity assessment in prepubertal children with high-frequency accelerometry monitoring: a methodological issue. Prev Med 2007;44:143147.

29 Leger LA, Mercier D, Gadoury C, Lambert J: The multistage 20 metre shuttle run test for aerobic fitness. J Sports Sci 1988;6:93-101.

-30 Ruiz J, Ortega F, Gutiérrez A, Meusel D, Sjöström M, Castillo M: Health-related fitness assessment in childhood and adolescence: a European approach based on the AVENA, EYHS and HELENA studies. J Public Health 2006;14:269-277.

-31 van Mechelen W, Hlobil H, Kemper HC: Validation of two running tests as estimates of maximal aerobic power in children. Eur J Appl Physiol Occup Physiol 1986;55:503-506.

-32 Ebenegger V, Marques-Vidal P, Barral J, Kriemler S, Puder JJ, Nydegger A: Eating habits of preschool children with high migrant status in Switzerland according to a new food frequency questionnaire. Nutr Res 2010; 30:104-109.

-33 Lasserre AM, Chiolero A, Cachat F, Paccaud F, Bovet P: Overweight in Swiss children and associations with children's and parents' characteristics. Obesity (Silver Spring) 2007;15:2912-2919.

-34 DuBose KD, Eisenmann JC, Donnelly JE: Aerobic fitness attenuates the metabolic synd rome score in normalweight, at-risk-for-overweight, and overweight children. Pediatrics 2007;120:e1262-1268.

-35 Eisenmann JC, Bartee RT, Smith DT, Welk GJ, Fu Q: Combined influence of physical activity and television viewing on the risk of overweight in US youth. Int J Obes (Lond) 2008;32:613-618.

36 Astrand PO, Rodahl K: Textbook of Work Physiology. New York, McGraw-Hill, 1977.

-37 Bar-Or 0: Physical activity and physical training in childhood obesity. J Sports Med Phys Fitness 1993;33: 323-329.

-38 Ara I, Vicente-Rodriguez G, Perez-Gomez J, Jimenez-Ramirez J, Serrano-Sanchez JA, Dorado C, Calbet JA: Influence of extracurricular sport activities on body composition and physical fitness in boys: a 3-year longitudinal study. Int J Obes (Lond) 2006;30:1062-1071.

-39 Martinez Vizcaino V, Salcedo Aguilar F, Franquelo Gutierrez R, Solera Martinez M, Sanchez Lopez M, Serrano Martinez S, Lopez Garcia E, Rodriguez Artalejo F: Assessment of an after-school physical activity program to prevent obesity among 9- to 10-year-old children: a cluster randomized trial. Int J Obes (Lond) 2008;32:12-22.

40 Moore LL, Lombardi DA, White MJ, Campbell JL, Oliveria SA, Ellison RC: Influence of parents' physical activity levels on activity levels of young children. J Pediatr 1991;118:215-219.

-41 Kalakanis LE, Goldfield GS, Paluch RA, Epstein LH: Parental activity as a determinant of activity level and patterns of activity in obese children. Res Q Exerc Sport 2001;72:202-209.

$\checkmark 42$ Cleland V, Venn A, Fryer J, Dwyer T, Blizzard L: Parental exercise is associated with Australian children's extracurricular sports participation and cardiorespiratory fitness: A cross-sectional study. Int J Behav Nutr Phys Act 2005;2:3. 